\title{
Frekuensi kelainan dento skeletal dengan penanganan bedah ortognatik dan osteodistraksi di rsup dr. Hasan sadikin bandung tahun 2012-2017
}

\author{
Arina Sani Nafisa*1 ${ }^{* 1}$ Abel Tasman Yuza ${ }^{1}$, Seto Adiantoro Sadputranto ${ }^{1}$ \\ ${ }^{1}$ Departemen Bedah Mulut, Fakultas Kedokteran Gigi, Universitas Padjadjaran, Indonesia
}

*Korespondensi: arina.sani@yahoo.co.id

\begin{abstract}
ABSTRAK
Pendahuluan : Kelainan dento skeletal adalah kelainan pada gigi geligi yang berdampak pada gangguan fungsi rahang, hubungan gigi dan penampilan wajah. Pada kelainan dento skeletal penggunaan alat ortodontik memiliki keterbatasan dalam mengoreksinya sehingga dibutuhkan perawatan bedah. Bedah ortognatik dan osteodistraksi merupakan pilihan perawatan yang dapat dijalani. Saat ini, RSUP Dr. Hasan Sadikin Bandung merupakan salah satu pusat rujukan nasional yang menyediakan bedah ortognatik dan osteodistraksi. penelitian ini adalah memberikan gambaran serta jumlah kelainan dento skeletal dengan penanganan bedah ortognatik dan osteodistraksi di SMF Bedah Mulut dan Maksilofasial pada periode 2012 - 2017. Metode : Metode penelitian yang digunakan adalah dekriptif retrospektif. Sample penelitian ini adalah rekam medis pasien kasus kelainan dento skeletal dengan penanganan bedah ortognatik dan osteodistraksi di SMF Bedah Mulut dan Maksilofasial RSUP Dr. Hasan Sadikin Bandung periode tahun 2012 - 2017 yang dipilih dengan pendekatan purposive sampling. Hasil : Hasil penelitian menunjukan kelainan dento skeletal dengan jumlah kasus penanganan bedah ortognatik paling banyak terjadi pada tahun 2017, berjumlah 19 kasus. Jumlah kasus penanganan osteodistraksi paling banyak terjadi pada tahun 2017, sebanyak 2 kasus. Teknik pembedahan ortognatik yang paling sering digunakan adalah kombinasi Le Fort 1 dan BSSO yaitu sebanyak 64,11\% sedangkan untuk teknik pembedahan osteodistraksi yang paling sering digunakan adalah teknik distraksi mandibular sebanyak 50\%. Simpulan : Pasien kelainan dento skeletal sebanyak 162 orang yang ditangani di SMF Bedah Mulut dan Maksilofasial RSUP Dr. Hasan Sadikin dengan bedah ortognatik sebanyak 39 orang (24\%) dan 4 orang $(2,5 \%)$ untuk osteodistraksi pada periode 2012 -2017.
\end{abstract}

Kata kunci: Kelainan dento skeletal, bedah ortognatik, bedah osteodistraksi

\section{Frequency of dento skeletal deformities with orthognatic and osteodistraction surgery at DR. RSUP Hasan Sadikin Bandung 2012-2017}

\begin{abstract}
Introduction : Abnormalities of dento skeletal are an anomaly on teeth which effect the jaw malfunction, the relationship of teeth and the facial appearance. The use of orthodontics tools in dento skeletal abnormality has limitation on the corrections, so the surgical treatment is needed. Orthognatic and osteodistraction surgery are an optional treatment to undertake. Currently RSUP Dr. Hasan Sadikin Bandung is the one of national referral center in handling orthognatic and osteodistraction surgery. The purpose of this study is to provide an overview and number of dento skeletal abnormailities with orthognatic and osteodistraction surgical treatment in SMF Oral and Maksilofacial Surgery within the 2012 - 2017 period. Methods: This study is using the descriptive retrospective method. The sample used are medical records of dento skeletal abnormalities with orthognatic and osteodistraction treatment case at SMF Oral and Maksilofacial Surgery RSUP Dr. Hasan Sadikin Bandung within 2012 - 2017 period which are selected using the purposive sampling approach. Results: The study shows that dento skeletal deformitiess with the highest number of orthognathic surgery cases occurred in 2017, totaling 19 cases. Meanwhile, the highest number osteodistraction cases occurred in 2017, as many as 2 cases. The most used orthognathic surgical technique is a combination of Le Fort 1 and BSSO which is as much as 64.11\% while the most commonly used osteodistractic surgery technique is mandibular distraction technique as much as 50\%. Conclusion: There are 162 dento skeletal deformities patients were treated at SMF Oral and Maxillofacial Surgery in Dr. Hasan Sadikin Hospital with orthognathic surgery as many as 39 people (24\%) and 4 people (2.5\%) for osteodistraction in the period 2012-2017.
\end{abstract}

Keywords: Dento skeletal deformities, orthognatic surgery, osteodistraction surgery 


\section{PENDAHULUAN}

Kelainan dento skeletal adalah kelainan pada gigi geligi yang disebabkan adanya ketidakseimbangan posisi, ukuran, bentuk atau orientasi tulang yang membentuk maksila dan mandibular. Kelainan dento skeletal dapat berdampak pada gangguan fungsi rahang,hubungangigidanpenampilanwajah.Kelainan tersebut dapat terjadi pada satu rahang atau mungkin melibatkan beberapa struktur kraniofasial.

Kelainan ini dapat secara unilateral atau bilateral, dan dapat dinyatakan ke tingkat yang bervariasi pada bidang fasial horisontal, vertikal dan transversal. ${ }^{1}$ Maloklusi merupakan salah satu keadaan yang menandakan adanya abnormalitas dento skeletal yang mengganggu fungsi pengunyahan, penelanan, berbicara serta keserasian wajah. Di Indonesia, prevalensi maloklusi mencapai $80 \%$ serta menjadi masalah kesehatan gigi dan mulut ketiga setelah karies dan penyakit periodontal.

Berdasarkan penelitian pada anak SMPN 4 dan SMAN 4 di Banjarbaru, terdapat $80 \%$ anak memiliki makloklusi berat sehingga mengganggu kesehatan fisik dan kehidupan sosialnya. ${ }^{2}$ Pasien dengan kelainan dento skeletal sering terjadi dengan asimetri wajah dan laporan sebelumnya menunjukkan bahwa sekitar $21 \%-67 \%$ pasien dengan prognati atau retrognati memiliki asimetri wajah. ${ }^{3}$ Kelainan dento skeletal ini juga dapat menimbulkan masalah fungsional seperti adanya gangguan pengucapan, mastikasi dan gangguan pada TMJ (Temporomandibular Joint) dimana hal tersebut dapat mengganggu aktivitas penderita.

Pada kelainan dento skeletal penggunaan alat-alat ortodontik memiliki keterbatasan dalam mengoreksinya sehingga dibutuhkan perawatan bedah. Bedah ortognatik merupakan pilihan perawatan yang dapat dijalani apabila terdapat kelainan pada maksila, mandibula, ataupun keduanya dan juga midfasial untuk mencapai keseimbangan wajah. ${ }^{4}$ Keuntungan dengan penanganan ini yaitu pemotongan yang dibutuhkan lebih sederhana melibatkan struktur pembuluh darah dan saraf yang lebih sedikit, serta menghindari terbentuknya jaringan parut pada muka dan leher. ${ }^{5}$ Selain dengan bedah ortognatik biasanya dilakukan juga osteodistraksi. Osteodistraksi adalah suatu teknik bedah dengan dilakukannya peregangan secara bertahap diantara kedua permukaan tulang yang telah dilakukan osteotomi untuk pembentukan tulang yang baru. ${ }^{5}$ Saat ini, RSUP Dr. Hasan Sadikin Bandung merupakan salah satu pusat rujukan nasional yang dilengkapi dengan pelayanan spesialistik dan sub spesialistik termasuk spesialis bedah mulut dan maksilofasial serta menyediakan penanganan bedah ortognatik.

Sehubungan dengan uraian diatas, tujuan dari penelitian ini adalah untuk memberikan gambaran serta jumlah kelainan dento skeletal dengan penanganan bedah ortognatik dan osteodistraksi di SMF Bedah Mulut dan Maksilofasial pada periode 2012 - 2017.

\section{METODE}

Metode yang digunakan pada penelitian ini adalah deskriptif restoratif. Populasi dalam penelitian ini adalah seluruh rekam medis pasien di bagian Bedah Mulut dan Maksilofasial RSUP Dr. Hasan Sadikin Bandung periode tahun 2012 - 2017 sedangkan yang menjadi sampelnya adalah rekam medis pasien dengan kasus kelainan dento skeletal dengan penanganan bedah ortognatik dan osteodistraksi yang diambil dengan pendekatan purposive sampling, instrumen yang dipakai yaitu rekam medis, alat tulis dan laptop, penelitian ini dilakukan di bagian rekam medis RSUP Dr. Hasan Sadikin Bandung pada bulan Maret - April 2018, Pengolahan data dilakukan dengan cara mengumpulkan berkas rekam medis pasien yang terdapat di bagian rekam medis RSUP Dr. Hasan Sadikin Bandung pada periode 2012 2017, kemudian diambil data pasien kelainan dento skeletal dengan penanganan bedah ortognatik dan osteodistraksi lalu diklasifikasikan berdasarkan umur, jenis kelamin, teknik pembedahan dan klasifikasi kelainannya, data yang didapat akan diolah berdasarkan frekuensinya dan cara penanganannya, kesimpulan didapat dari hasil analisis data., analisis data dilakukan dengan menggunakan distribusi frekuensi relative.

\section{HASIL}

Hasil penelitian menggambarkan pasien bedah ortognatik paling banyak pada tahun 2017 yaitu sebanyak 19 orang dan bedah osteodistraksi di tahun 2017 sama jumlahnya dengan tahun 2015 yaitu berjumlah 2 orang. Jumlah pasien yang menjalani perawatan bedah ortognatik dan osteodistraksi pada setiap tahunnya dapat dilihat pada tabel 1 . 
Pada tabel 2 menunjukan kasus bedah ortognatik dan osteodistraksi di SMF Bedah Mulut RSUP Dr. Hasan Sadikin Bandung selama periode 2012 - 2017 penderita laki-laki lebih banyak dari perempuan yaitu sebanyak 24 orang .

Berdasarkan kelompok umur, kasus bedah ortognatik dan osteodistraksi ini terbanyak didapat pada kelompok umur 16 -20 yaitu 18 kasus untuk ortognatik dan 3 pada kasus osteodistraksi. Hasil penelitian mengenai distribusi kasus bedah ortognati berdasarkan kelompok umur ini dapat dilihat pada tabel berikut ini (Tabel 3). Klasifikasi kelainan yang paling banyak dialami oleh pasien bedah ortognatik yaitu disgnati kelas III sebanyak 17 orang (43,58\%) seperti pada tabel 4. Sedangkan untuk pasien bedah osteodistraksi adalah retrognati maksila sebanyak 2 orang (25\%). Terdapat beberapa teknik pembedahan yang dilakukan pada pelaksanaan bedah ortognatik dan osteodistraksi di SMF Bedah Mulut dan Maksilofasial RSUP Dr. Hasan Sadikin Bandung periode 2012 -2017.

Teknik pembedahan yang terbanyak dilakukan yaitu Kombinasi Osteotomi Le Fort 1 dengan BSSO seperti terlihat pada tabel 6. Pada bedah osteodistraksi teknik distraksi mandibular yang paling sering digunakan. (Tabel 7)

Tabel 1 distribusi frekuensi kelainan dento skeletal dengan penanganan bedah ortognatik dan osteodistraksi rsup dr. Hasan sadikin bandung tahun $2012-2017$

\begin{tabular}{cccc}
\hline & & Jumlah Pasien & Osteodistraksi \\
\cline { 3 - 4 } & Tahun & Ortognatik & 0 \\
2012 & 4 & 4 & 0 \\
2014 & 3 & 5 & 2 \\
2015 & 4 & 0 \\
2016 & 19 & 2 \\
2017 & 39 & 4 \\
\hline
\end{tabular}

Tabel 2 distribusi frekuensi kelainan dento skeletal dengan penanganan bedah ortognatik dan osteodistraksi rsup dr. Hasan sadikin bandung tahun $2012-2017$

\begin{tabular}{|c|c|c|c|c|}
\hline \multirow{2}{*}{ Jenis Kelamin } & \multicolumn{2}{|c|}{ Ortognatik } & \multicolumn{2}{|c|}{ Osteodistraksi } \\
\hline & $\mathbf{n}$ & $\%$ & $\mathbf{n}$ & $\%$ \\
\hline Pria & 24 & $61,54 \%$ & 3 & $75 \%$ \\
\hline Wanita & 15 & $38,46 \%$ & 1 & $25 \%$ \\
\hline Total & 39 & $100 \%$ & 4 & $100 \%$ \\
\hline
\end{tabular}

Tabel 3 distribusi frekuensi kelainan dento skeletal dengan penanganan bedah ortognatik dan osteodistraksi rsup dr. Hasan sadikin bandung tahun $2012-2017$ berdasarkan umur

\begin{tabular}{|c|c|c|c|c|}
\hline \multirow{2}{*}{ Umur } & \multicolumn{2}{|c|}{ Ortognatik } & \multicolumn{2}{|c|}{ Osteodistraksi } \\
\hline & $\mathbf{n}$ & $\%$ & $\mathbf{n}$ & $\%$ \\
\hline$<15$ & 1 & $2,56 \%$ & 1 & $25 \%$ \\
\hline $16-20$ & 18 & $46,15 \%$ & 3 & $75 \%$ \\
\hline $21-25$ & 11 & $28,20 \%$ & 0 & $0 \%$ \\
\hline $26-30$ & 6 & $15,38 \%$ & 0 & $0 \%$ \\
\hline$>30$ & 3 & $7,69 \%$ & 0 & $0 \%$ \\
\hline Total & 39 & $100 \%$ & 4 & $100 \%$ \\
\hline
\end{tabular}


Tabel 4 distribusi frekuensi kelainan dento skeletal dengan penanganan bedah ortognatik dan osteodistraksi rsup dr. Hasan sadikin bandung tahun $2012-2017$ berdasarkan klasifikasi kelainan

\begin{tabular}{ccc}
\hline Klasifikasi Kelainan & Ortognatik \\
\cline { 2 - 3 } Disgnati Kelas 1 & $\mathbf{n}$ & $2,56 \%$ \\
Disgnati Kelas II & 1 & $10,25 \%$ \\
Disgnati Kelas III & 4 & $43,58 \%$ \\
Hipoplasia Maxilla Posterior & 17 & $2,56 \%$ \\
Prognati Mandibula & 1 & $10,25 \%$ \\
Hipoplasia Mandibula & 4 & $2,56 \%$ \\
Hiperplasia Mandibula + Asimetri & 1 & $2,56 \%$ \\
Laterognatik & 1 & $7,69 \%$ \\
Pan Fasial Fraktur Pasca Perawatan & 3 & $2,56 \%$ \\
Retrognati Maxilla & 1 & $2,56 \%$ \\
Fraktur Le Fort 1 & 1 & $2,56 \%$ \\
Open Bite & 1 & $2,56 \%$ \\
\hline Total & 1 & $\mathbf{1 0 0 \%}$ \\
\hline
\end{tabular}

Tabel 5 distribusi frekuensi kelainan dento skeletal dengan penanganan bedah osteodistraksi rsup dr. Hasan sadikin bandung tahun 2012 -2017 berdasarkan klasifikasi kelainan

\begin{tabular}{ccc}
\hline \multirow{2}{*}{ Klasifikasi Kelainan } & \multicolumn{3}{c}{ Osteoditraksi } \\
\cline { 2 - 3 } & $\mathbf{N}$ & $\mathbf{0}$ \\
\hline Retrognati Maxila & 2 & $25 \%$ \\
Sindrom Appert & 1 & $25 \%$ \\
Mandibula Disorder & 1 & $50 \%$ \\
\hline Total & $\mathbf{4}$ & $\mathbf{1 0 0 \%}$ \\
\hline
\end{tabular}

Tabel 6 distribusi frekuensi kelainan dento skeletal dengan penanganan bedah ortognatik rsup dr. Hasan sadikin bandung tahun $2012-2017$ berdasarkan teknik pembedahan

\begin{tabular}{ccc}
\hline Teknik Pembedahan & \multicolumn{2}{c}{ Ortognatik } \\
\cline { 2 - 3 } & n & \% \\
\hline BSSO & 8 & $20,51 \%$ \\
BSSO + Chinplasty + Le Fort 1 & 1 & $2,56 \%$ \\
Osteotomi Le Fort 1 & 4 & $10,26 \%$ \\
Osteotomi Le Fort 1 + BSSO & 25 & $64,11 \%$ \\
Genioplasty & 1 & $2,56 \%$ \\
\hline Total & $\mathbf{3 9}$ & $\mathbf{1 0 0 \%}$ \\
\hline
\end{tabular}

Tabel 7 distribusi frekuensi kelainan dento skeletal dengan penanganan bedah osteodistraksi rsup dr. Hasan sadikin bandung tahun $2012-2017$ berdasarkan teknik pembedahan

\begin{tabular}{ccc}
\hline Teknik Pembedahan & \multicolumn{2}{c}{ Ortognatik } \\
\cline { 2 - 4 } & $\mathbf{n}$ & $\mathbf{\%}$ \\
\hline Distraksi Mandibula & 1 & $25 \%$ \\
Distraksi Maksila & 2 & $50 \%$ \\
Distraksi Mid Facial & 1 & $25 \%$ \\
\hline \multirow{2}{*}{ Total } & $\mathbf{4}$ & $\mathbf{1 0 0 \%}$ \\
\hline
\end{tabular}




\section{PEMBAHASAN}

Dari hasil penelitian mengenai bedah ortognatik yang dirawat di SMF Bedah Mulut dan Maksilofasial RSUP Dr. Hasan Sadikin Bandung dalam kurun waktu 2012 - 2017 diperoleh bahwa 24\% kelainan dento skeletal ditangani dengan bedah ortognatik dan 2,5\% ditangani osteodistraksi. Hal ini menunjukan bahwa bedah ortognatik banyak digunakan untuk penanganan kelainan dento skeletal yang mencakup rahang (maksila dan mandibula), midfasial, dan keadaan gigi yang mengganggu aspek fungsional dan estetika pasien itu sendiri.

Berdasarkan hasil penelitian dapat dilihat bahwa terdapat peningkatan yang signifikan di tahun 2017 dibandingkan tahun-tahun sebelumnya seperti pada tabel 1, tahun-tahun sebelumnya hanya ratarata berkisar 4 kasus per tahun dan pada tahun 2017 menjadi 19 kasus per tahun. Hal ini dapat disebabkan karena mulai bertambahnya informasi mengenai bedah ortognatik di kalangan masyarakat sehingga lebih memahami bahwa untuk mereposisi kelainan dento skeletal dapat dilakukan dengan pendekatan operasi yang hasilnya memungkinkan untuk cepat terkoreksinya gangguan dento skeletal.

Sedangkan bedah osteodistraksi jumlah kasus masih sangat minim yaitu berjumlah 4 kasus, hal ini dapat disebabkan karena bedah ini diindikasikan untuk kelainan disgnati mandibula dan maksila yang parah, asimetris wajah, ankilosis sendi yang parah, dan juga sindrom-sindrom seperti sindrom Crouzon dan sindrom Apert serta dibutuhkan biaya yang mahal untuk penanganan osteodistraksi ini. RSUP Dr. Hasan Sadikin Bandung merupakan rumah sakit rujukan dan salah satu rumah sakit yang mampu menangani kasus bedah ortognatik dan osteodistraksi sebab dibutuhkan para operator, perawat serta alat-alat yang menunjang dalam penanganan bedah ini.

Berdasarkan tabel 2 bahwa kasus bedah ortognatik dan osteodistraksi ini lebih banyak laki-laki dibandingkan dengan wanita, pada kasus ortognatik perbandingannya adalah $8: 5$. Sedangkan pada osteodistraksi 3 : 1 dengan kondisi jumlah laki-laki lebih banyak dibanding wanita. Pada penelitian-penelitian sebelumnya menunjukan bahwa pasien lebih banyak wanita dibandingkan laki-laki yang dikaitkan dengan indikasi dalam segi estetik yang dibutuhkan masyarakat.,7,8 Pada penelitian ini jumlah kasus laki-laki lebih banyak dibandingkan wanita, hal ini dapat dikaitkan bahwa segi fungsional lebih diutamakan dalam indikasi bedah ortognatik dan osteoditraksi, hal ini diperkuat dengan melihat hasil anamnesa yang menunjukan hampir sebagian besar mengeluhkan aspek fungsional dan menjadikannya keluhan utama dalam melakukan perawatan bedah ortognatik dan osteodistraksi. Masalah fungsional yang ditemukan dalam penelitian ini adalah fungsi bicara terganggu, pegal dan sakit sendi, sakit kepala dan yang paling banyak adalah fungsi pengunyahan yang tergangu. Dalam beberapa penelitan menyatakan masalah fungsional merupakan indikasi utama pada $36-55 \%$ pasien. ${ }^{9,10}$ Masalah fungsional terbagi dalam masalah berbicara, menelan, mengunyah, sakit pada TMJ dll.

Secara keseluruhan, penelitian-penelitian tersebut menunjukkan bahwa gangguan fungsi merupakan indikasi utama untuk bedah ortognatik dan osteodistraksi. Pada tabel 3 dapat dilihat bahwa dari 39 kasus bedah ortognatik dan 4 kasus bedah osteodistraksi, pasien paling banyak berumur 16 20 tahun yaitu sebanyak 18 kasus bedah ortognatik dan 3 kasus bedah osteodistraksi, lalu diikuti oleh umur 21 - 25 tahun sebanyak 11 kasus pada bedah ortognatik. Hal ini dikarenakan dalam pembedahan ini ditujukan pada saat pertumbuhan tulang sudah berhenti untuk meminimalkan

Perubahan yang mungkin terjadi pascabedah. Umur lainnya yaitu pada umur dibawah 15 tahun berjumlah 1 orang, pembedahan ini bersifat sementara yang disebabkan koreksi pembedahan yang dilakukan terlalu awal dapat dengan mudah menyebabkan kekambuhan karena pertumbuhan mandibula residual atau diperlukannya pembedahan lanjutan. ${ }^{11}$ Sedangkan pasien bedah ortognatik yang berumur diatas 25 tahun yang berjumlah 9 orang mungkin baru mengetahui mengenai bedah ortognatik saat -saat ini atau keadaan sosial ekonomi yang baru memungkinkan karena dibutuhkan biaya yang cukup mahal untuk perawatan bedah ortognatik maupun osteodistraksi. Tabel 4 menunjukan dari 39 kasus bedah ortognatik, disgnati kelas III merupakan klasifikasi terbanyak yaitu berjumlah 17 kasus $(43,58 \%)$, dapat disebabkan karena kasus disgnati kelas III cukup kompleks dimana alat ortodontik memiliki keterbatasan dalam mengoreksinya sehingga dibutuhkan perawatan bedah. Penderita disgnati kelas III terganggu fungsi pengunyahan dan 
pengucapannya dibandingkan jenis disgnati lainnya. ${ }^{6}$ Diikuti klasifikasi lainnya yaitu disgnati kelas II dan prognati mandibula sebanyak 4 kasus $(10,25 \%)$, lalu laterognatik sebanyak 3 kasus (7,69\%), sedangkan hipoplasia maxilla posterior, hipoplasia mandibula, hiperplasia mandibula, pan fasial fraktur pasca perawatan,retrognati maxilla, fraktur le fort 1 , open bite masing masing berjumlah 1 kasus (2,56\%).

Tabel 5 menunjukan dari 4 kasus bedah osteodistraksi, retrognati maxilla ini jumlahnya lebih banyak yaitu sejumlah 2 kasus (50\%). Sedangkan kelainan yang lainnya adalah mandibular disorder dan sindrom appert masing-masing berjumlah 1 kasus (25\%). Hal ini disebabkan karena sindrom appert ini prevalensi kelahirannya sebesar 1/65000. 12 Berdasarkan tabel 6, teknik pembedahan ortognatik yang paling sering dilakukan adalah Bilateral Sagital Split Osteotomy yang dikombinasikan dengan osteotomi Le Fort 1, yaitu sebanyak 25 kasus $(64,11 \%)$ dari 39 kasus bedah ortognatik di SMF Bedah Mulut dan Maksilofasial RSUP Dr. Hasan Sadikin dalam periode 2012 - 2017. Hal ini sesuai dengan penelitian Prosedur pembedahan yang paling sering digunakan untuk mengoreksi rahang adalah osteotomi Le Fort I dan Osteotomi Sagital Ramus Split ${ }^{4}$ ini dikarenakan dalam suatu disgnati, kelainan bisa berasal dari dua rahang ekstrim.

Selanjutnya diikuti teknik Bilateral Sagital Split Osteotomy (BSSO) berjumlah 8 kasus (20,51\%).

Teknik ini merupakan teknik yang paling sering digunakan pada kasus pembedahan mandibular Bedah ini bertujuan untuk memperbaiki kelainan rahang serta mengembalikan fungsi estetiknya. Teknik ini biasa digunakan untuk memperbaiki retrognati dan prognati mandibula, dan dalam beberapa kasus penutupan open bite. ${ }^{13}$

Lalu Osteotomi Le fort 1 sebanyak 4 kasus $(10,26 \%)$ sedangkan teknik kombinasi BSSO, genioplasty dan Le Fort 1 serta kasus bedah genioplasty saja masing - masing berjumlah 1 kasus (2,56\%) dikarenakan teknik genioplasty ini hanya prosedur tambahan yang dapat dilakukan bersamaan dengan bedah ortognatik untuk memperbaiki bentuk dagu dengan memajukan, memperpendek, atau memanjangkan dagu atau menyesuaikan dagu dengan posisi garis tengah untuk meningkatkan keseimbangan profil-metrik sempurna dan keharmonisan wajah umum serta estetika wajah yang ditentukan oleh keseimbangan struktural berbagai area anatomi dan juga memperbaiki aliran udara melalui hidung pasien. Keuntungan lainnya adalah meningkatkan otot suprahyoid dan meningkatkan retroglossal space, sehingga memperbaiki saluran napas pasien. 12 Pada tabel 7 menunjukan teknik yang lebih sering digunakan pada bedah osteodistraksi adalah teknik distraksi maxilla yaitu sebanyak 2 kasus sedangkan teknik distraksi mandibula dan midfasial masing-masing berjumlah 1 kasus. Osteodistraksi ini dilakukan karena celah yang dihasilkan setelah dilakukannya osteotomi yaitu lebih dari $7 \mathrm{~mm}$. Jaringan kalus yang dihasilkan di celah distraksi akhirnya akan menghasilkan mineralisasi, menciptakan jembatan baru jaringan tulang di antara tepi osteotomi dari segmen tulang asli.. ${ }^{14}$

\section{SIMPULAN}

Pasien kelainan dento skeletal sebanyak 162 orang yang ditangani di SMF Bedah Mulut dan Maksilofasial RSUP Dr. Hasan Sadikin dengan bedah ortognatik sebanyak 39 orang (24\%) dan 4 orang $(2,5 \%)$ untuk osteodistraksi pada periode 2012 -2017. Pasien bedah ortognatik dan osteodistraksi lebih banyak laki-laki dan usia 16-20 tahun.

Kelainan dento skeletal paling banyak berupa disgnati kelas III yaitu 43,58\% pada kasus bedah ortognatik dan retrognati maksila sebanyak $50 \%$ pada osteodistraksi. Bedah kombinasi osteotomi Le Fort 1 dan BSSO merupakan teknik yang paling sering digunakan untuk mengoreksi kelainan dento skeletal ini yaitu sebanyak 64,11\%. Pada kasus osteodistraksi, teknik distraksi maksila yang lebih banyak digunakan dibanding yang lainnya yaitu berjumlah $50 \%$.

\section{DAFTAR PUSTAKA}

1. Gonzalo, M. TMJ in Facial Class III Deformity: Condylar morphology relations. Int J Clin Exp Med 2014 7(9):3113-3117.

2. Fajar, et al. Hubungan Antara Kebiasaan Buruk Bernafas Melalui Mulut dan Tingkat Keparahan Maloklusi di SMPN 4 dan SMAN 4 Banjarbaru. Banjarmasin : Dentino Jurnal Kedokteran Gigi ; 2017

3. Eslamipour, F. et al. A Retrospective Analysis of Dentofacial Deformities and Orthognatic Surgeries. Annals of Maxillofacial Surgery. 2017 Jan-Jun;7(1): 264-269.

4. Kjaergaard, Marie. Indications for Orthognatic 
Surgery. OHDM 2017 Vol 16: No-2.

5. Peterson. Peterson's Principle of Oral and Maxillofacial Surgery. $2^{\text {nd }}$ ed. London: BC Decker Inc ; 2004.

6. Claudio et al. Aesthetic Restoration in Maxillomandibular malformations: The Role of Genioplasty. Annali di Stomatologia. 2015VI(34):110-112

7. D. Ceverlli et al. Lipofilling as Refinement Procedure in Maxillo-Mandibular Malformations. Acta Otorhinolaryngologica Italica. 2016 36:368372

8. EspelandL, Hogevold HE, Stenvik A. A 3-Year Patient-Centred Follow Up Of 516 Consecutively Treated Orthognatic Surgery Patient. Europian Journal of Orthodontics. 2008 30: 24-30

9. Proothi M, Drew SJ, Sachs S a. Motivating Factors for Patients Undergoing Orthognatic Surgery Evaluation. Journal of Oral and Maxillofacial surgery. 2010 68: 1555-1559.

10. Chen B, Zhang Z, Wang X. Factors influencing postoperative satisfaction of Orthognatic Surgery Patients. The International Journal of Adult Orthodontics \& Orthognatic Surgery. 2002 17: $217-222$.

11. Paolo Ronchi and Alberto Guariglia. Surgical Orthodontic Treatment of Class III Malocclusions. Principles in Contemporary Orthodontics. Dr. Silvano Naretto (Ed.), 2011 ISBN: 978-953-307687-4

12. Anatoli et al. Apert Syndrome. Internasional Journal of Dermatology. 2006 45: 1341 -1343

13. Hoshein, K., et al. Osteotomies in Orthoghnatic Surgery. Intech Openminds ; 2016

14. Ayman et al. Distraction Osteogenesis of the Maxillofacial Skeleton: Biomechanics and Clinical Implications. Open Access Scientific Reports. 2012 Vol.1:Issue 11 